\title{
Evaluating the performance of the land surface model ORCHIDEE-CAN on water and energy flux estimation with a single- and a multi- layer energy budget scheme
}

Yiying Chen, James Ryder, Vladislav Bastrikov, Matthew J. McGrath, Kim Naudts, Juliane Otto, Catherine Ottlé , Philippe Peylin, Jan Polcher, Aude Valade, Andrew Black, Jan A. Elbers, Eddy Moors, Thomas Foken, Eva van Gorsel, Vanessa Haverd, Bernard Heinesch, Frank Tiedemann, Alexander Knohl, Samuli Launiainen, Denis Loustau , Jérôme Ogée, Timo Vessala, and Sebastiaan Luyssaert

\section{Supplementary information}

This document contains the supplementary tables and figures of the manuscript 'Evaluating the performance of the land surface model ORCHIDEE-CAN (revision 2754) on water and energy fluxes estimation with a single- and multi- layer energy budget scheme'. 
Table S1. Description of the experimental design. The model was forced either by the site-level observations (SITE) or the CRU-NCEP re-analysis (CRU) and was run with the single-layer energy budget scheme (SINGLE) or the multi-layer energy budget scheme (MULTI). The model could be forced to follow the observed $L A I$ profiles (IMPOSE) or made use of the internal calculation of the seasonal dynamics and vertical profile of $L A I$ (SIM). EXP denotes the experiment name, PERIOD refers to the periods for which the simulations were run as defined in Table 3.

\begin{tabular}{|c|c|c|c|c|c|c|c|}
\hline \multirow[t]{2}{*}{ EXP } & \multicolumn{2}{|c|}{ FORCING } & \multicolumn{2}{|c|}{ ENERGY BUDGET } & \multicolumn{2}{|c|}{ LAI PROFILE } & \multirow[t]{2}{*}{ PERIOD } \\
\hline & SITE & CRU & SINGLE & MULTI & IMPOSE & SIM & \\
\hline SPINUP & & + & + & & & + & $20 \mathrm{yrs}$ \\
\hline optimizE & + & & + & & + & & I \& II \\
\hline EXP1 & + & & + & & + & & III \\
\hline EXP2 & + & & + & & + & & IV \\
\hline EXP3 & + & & & + & + & & III \\
\hline EXP4 & + & & & + & + & & IV \\
\hline
\end{tabular}




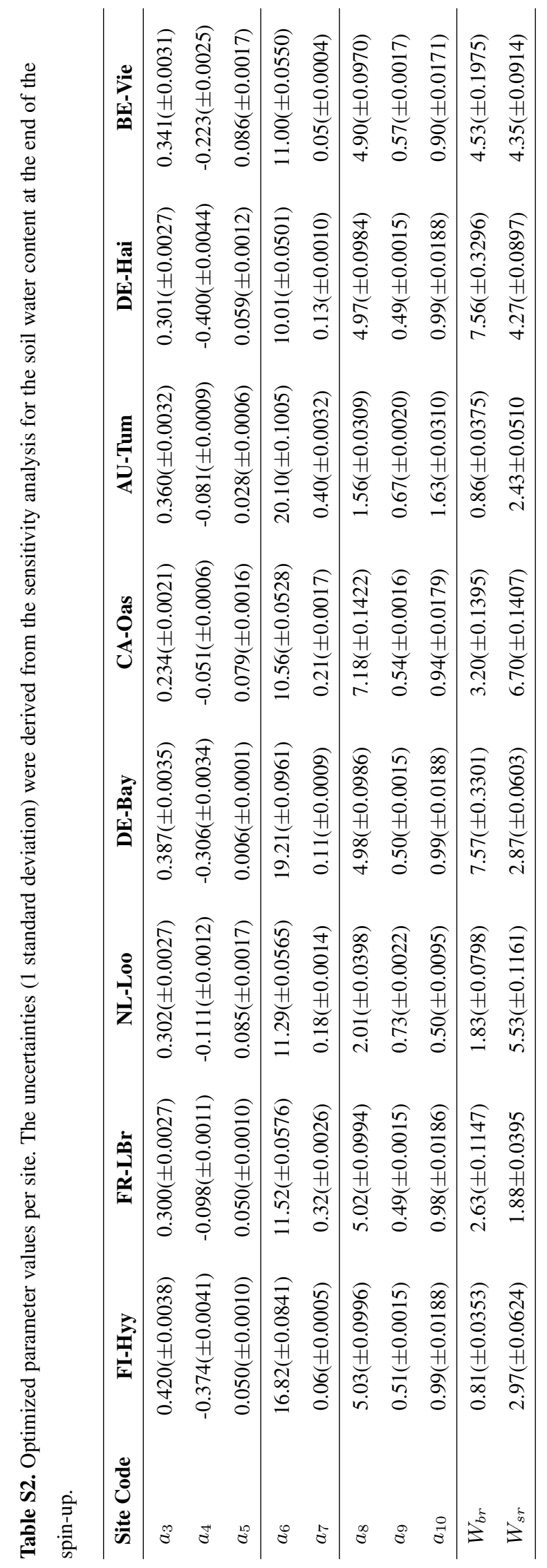


Table S3. Calibration results during observation Period I and II for each site.

\begin{tabular}{|c|c|c|c|c|c|}
\hline \multicolumn{4}{|c|}{ Period I } & \multicolumn{2}{|c|}{ Period II } \\
\hline Site & optimized & RMSE & RMSE & RMSE & RMSE \\
\hline Code & variable & prior(default) & optimized & prior(default) & optimized \\
\hline \multirow[t]{6}{*}{ AU-Tum } & $R_{n}$ & 51.4 & 51.9 & & \\
\hline & $L E$ & 86.6 & 38.9 & 39.5 & 44.8 \\
\hline & $H$ & 150.9 & 33.1 & 46.3 & 38.0 \\
\hline & $U$ & 0.15 & 0.07 & & \\
\hline & $T_{a}$ & 0.48 & 0.35 & & \\
\hline & $q_{a}$ & 0.00030 & 0.00027 & & \\
\hline \multirow[t]{6}{*}{ BE-Vie } & $R_{n}$ & 32.9 & 39.6 & & \\
\hline & $L E$ & 102.6 & 38.1 & 125.8 & 22.9 \\
\hline & $H$ & 97.3 & 44.8 & 127.7 & 36.6 \\
\hline & $U$ & 0.64 & 0.64 & & \\
\hline & $T_{a}$ & 0.61 & 0.86 & & \\
\hline & $q_{a}$ & 0.00087 & 0.00083 & & \\
\hline \multirow[t]{6}{*}{ CA-Oas } & $R_{n}$ & 35.1 & 34.1 & & \\
\hline & $L E$ & 54.0 & 34.7 & 150.9 & 66.7 \\
\hline & $H$ & 73.9 & 50.2 & 155.3 & 74.1 \\
\hline & $U$ & 0.25 & 0.21 & & \\
\hline & $T_{a}$ & 1.27 & 1.24 & & \\
\hline & $q_{a}$ & n.a. & n.a & & \\
\hline \multirow[t]{6}{*}{ DE-Bay } & $R_{n}$ & 33.3 & 33.3 & & \\
\hline & $L E$ & 76.3 & 74.7 & 128.1 & 27.8 \\
\hline & $H$ & 60.7 & 30.2 & 136.6 & 36.3 \\
\hline & $U$ & 0.62 & 0.21 & & \\
\hline & $T_{a}$ & 0.82 & 0.64 & & \\
\hline & $q_{a}$ & n.a. & n.a & & \\
\hline \multirow[t]{6}{*}{ DE-Hai } & $R_{n}$ & 21.0 & 24.7 & & \\
\hline & $L E$ & 138.6 & 35.7 & 87.4 & 38.6 \\
\hline & $H$ & 148.9 & 48.9 & 88.2 & 46.9 \\
\hline & $U$ & 2.05 & 1.21 & & \\
\hline & $T_{a}$ & 0.78 & 0.79 & & \\
\hline & $q_{a}$ & n.a. & n.a & & \\
\hline
\end{tabular}


Table S3. Continuation of Table $\mathrm{S3}$

\begin{tabular}{|c|c|c|c|c|c|}
\hline \multicolumn{4}{|c|}{ Period I } & \multicolumn{2}{|c|}{ Period II } \\
\hline Site & optimize & RMSE & RMSE & RMSE & RMSE \\
\hline Code & variable & prior(default) & optimized & prior(default) & optimized \\
\hline \multirow[t]{6}{*}{ FI-Hyy } & $R_{n}$ & 33.5 & 33.0 & & \\
\hline & $L E$ & 157.9 & 49.3 & 44.5 & 20.6 \\
\hline & $H$ & 155.5 & 52.5 & 46.9 & 31.5 \\
\hline & $U$ & 0.23 & 0.15 & & \\
\hline & $T_{a}$ & 1.15 & 1.14 & & \\
\hline & $q_{a}$ & 0.00024 & 0.00015 & & \\
\hline \multirow[t]{6}{*}{ FR-LBr } & $R_{n}$ & 27.4 & 25.6 & & \\
\hline & $L E$ & 89.4 & 49.5 & 44.5 & 44.4 \\
\hline & $H$ & 73.4 & 47.3 & 51.7 & 41.9 \\
\hline & $U$ & 0.17 & 0.15 & & \\
\hline & $T_{a}$ & 1.46 & 1.46 & & \\
\hline & $q_{a}$ & 0.00037 & 0.00038 & & \\
\hline \multirow[t]{6}{*}{ NL-Loo } & $R_{n}$ & 33.6 & 33.4 & & \\
\hline & $L E$ & 71.2 & 47.9 & 63.2 & 27.2 \\
\hline & $H$ & 122.4 & 56.9 & 63.9 & 43.6 \\
\hline & $U$ & 0.88 & 0.75 & & \\
\hline & $T_{a}$ & 0.81 & 0.78 & & \\
\hline & $q_{a}$ & 0.00072 & 0.00067 & & \\
\hline \multirow[t]{6}{*}{ All Sites } & $R_{n}$ & 33.5 & 34.5 & & \\
\hline & $L E$ & 91.2 & 46.1 & 85.5 & 37.4 \\
\hline & $H$ & 123.2 & 50.3 & 89.6 & 43.6 \\
\hline & $U$ & 0.62 & 0.42 & & \\
\hline & $T_{a}$ & 0.92 & 0.93 & & \\
\hline & $q_{a}$ & 0.00047 & 0.00043 & & \\
\hline
\end{tabular}


Table S4. Evaluation of the model performance, Taylor score $\left(S_{T}\right)$, correlation coefficient (R) and root mean square error (RMSE) for four experiments and changes in performance.

\begin{tabular}{|c|c|c|c|c|c|c|}
\hline Experiment & EXP1 & EXP2 & |EXP1-EXP2| & EXP3 & EXP4 & |EXP3-EXP4| \\
\hline \multicolumn{7}{|l|}{$\mathbf{R n}$} \\
\hline$S_{T}(0-1)$ & 0.961 & 0.931 & 0.030 & 0.893 & 0.924 & 0.031 \\
\hline $\mathrm{R}(0-1)$ & 0.986 & 0.874 & & 0.763 & 0.903 & \\
\hline $\operatorname{RMSE}\left(W m^{-2}\right)$ & 33.21 & 87.30 & & 113.1 & 64.31 & \\
\hline \multicolumn{7}{|l|}{$\mathbf{H}$} \\
\hline$S_{T}(0-1)$ & 0.863 & 0.828 & 0.035 & 0.780 & 0.844 & 0.064 \\
\hline $\mathrm{R}(0-1)$ & 0.777 & 0.689 & & 0.603 & 0.739 & \\
\hline $\operatorname{RMSE}\left(W m^{-2}\right)$ & 59.64 & 71.51 & & 50.64 & 46.87 & \\
\hline \multicolumn{7}{|l|}{$\mathbf{L E}$} \\
\hline$S_{T}(0-1)$ & 0.822 & 0.778 & 0.044 & 0.737 & 0.677 & 0.060 \\
\hline $\mathrm{R}(0-1)$ & 0.804 & 0.710 & & 0.549 & 0.588 & \\
\hline $\operatorname{RMSE}\left(W m^{-2}\right)$ & 48.06 & 56.44 & & 53.43 & 49.11 & \\
\hline \multicolumn{7}{|l|}{$\mathbf{G}$} \\
\hline$S_{T}(0-1)$ & 0.234 & 0.275 & 0.041 & 0.369 & 0.304 & 0.065 \\
\hline $\mathrm{R}(0-1)$ & 0.544 & 0.451 & & 0.358 & 0.497 & \\
\hline $\operatorname{RMSE}\left(W m^{-2}\right)$ & 23.64 & 24.83 & & 23.92 & 24.50 & \\
\hline
\end{tabular}



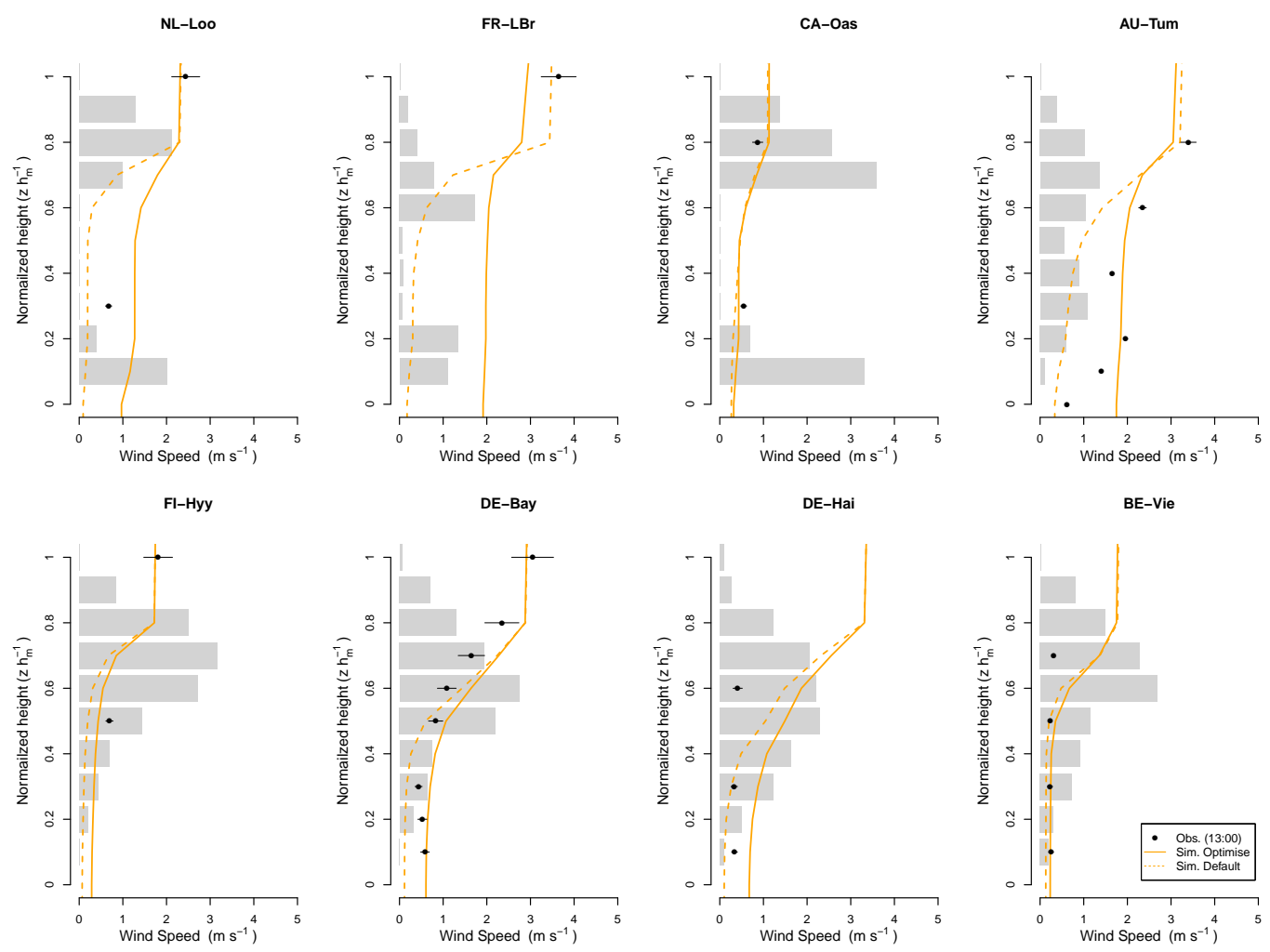

Figure S1. Model simulation and observation of the wind speed profile at eight forest sites during the shortterm campaign (Period I). All the dashed lines indicate the prior simulation with default parameter values and the solid lines present the optimized simulation with optimized parameter values. The filled circles are the observation means and the bars are stand deviations over the simulation period at 13:00. The gray bars in the background indicate the measured maximum LAI at each level in the reference year. 

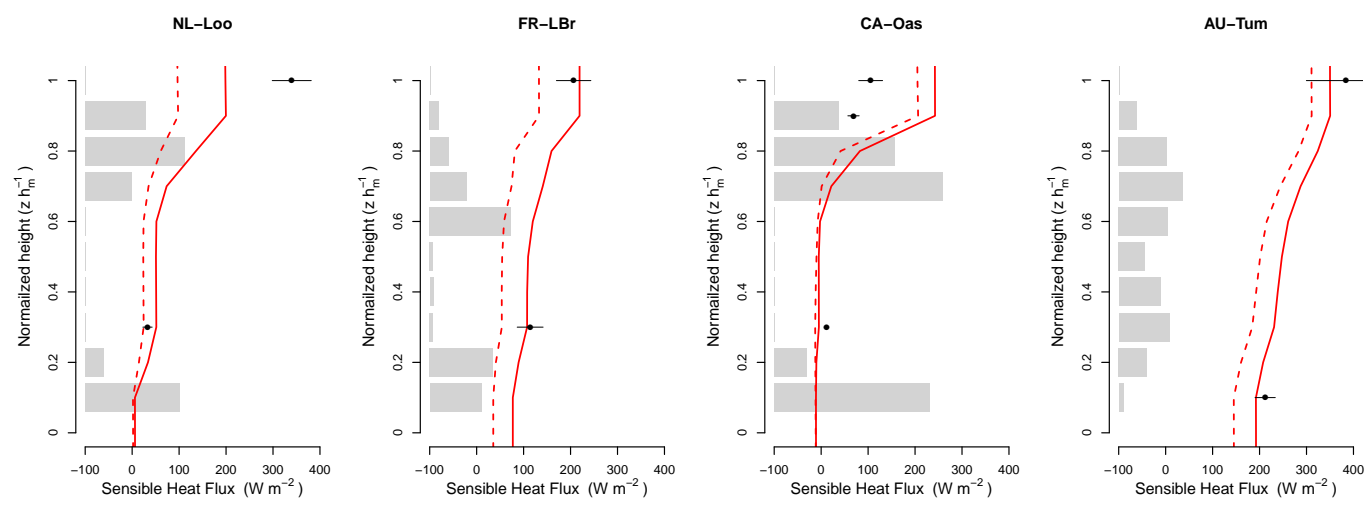

FI-Hyy

DE-Bay

DE-Hai

BE-Vie
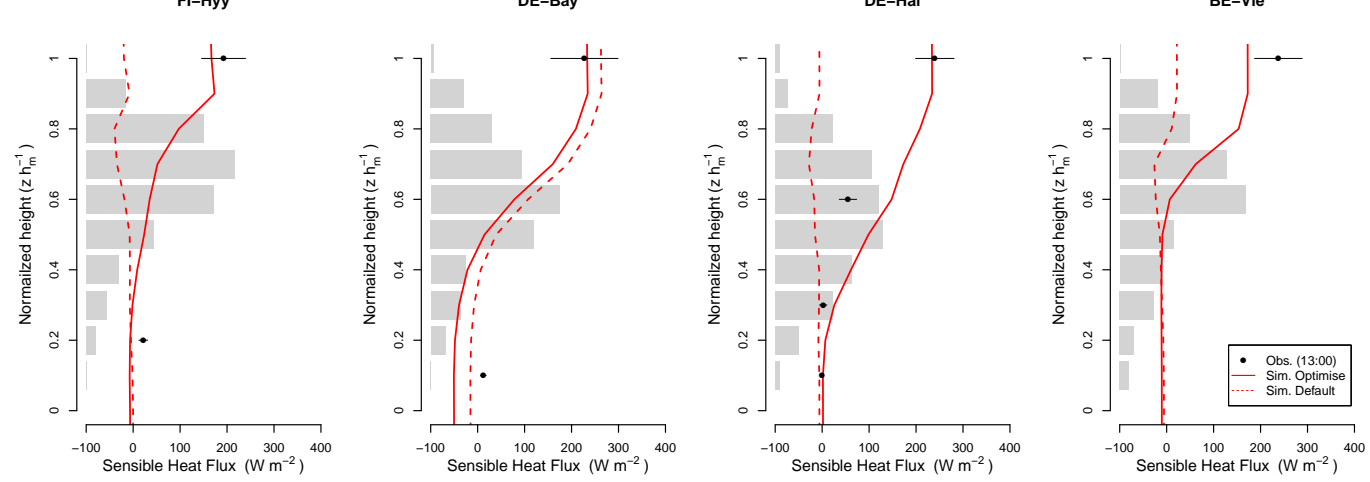

Figure S2. Model simulation and observation of the sensible heat flux profile at eight forest sites during the short-term campaign (Period I). All the dashed lines indicate the prior simulation with default parameter values and the solid lines present the optimized simulation with optimized parameter values. The filled circles are the observation means and the bars are stand deviations over the simulation period at 13:00. The gray bars in the background indicate the measured maximum LAI at each level in the reference year. 

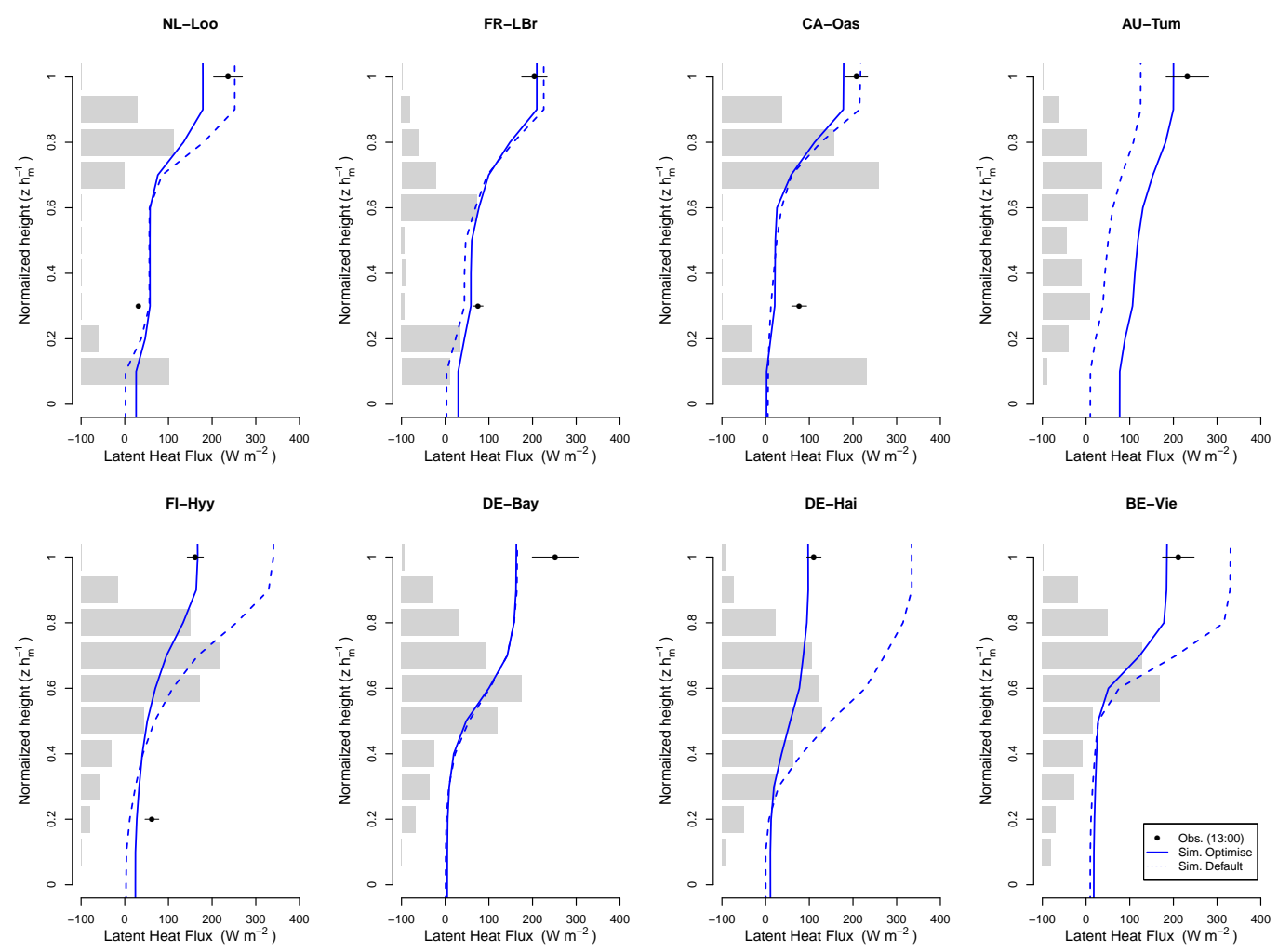

Figure S3. Model simulation and observation of the latent heat flux profile at eight forest sites during the short-term campaign (Period I). All the dashed lines indicate the prior simulation with default parameter values and the solid lines present the optimized simulation with optimize parameter values. The filled circles are the observation means and the bars are stand deviations over the simulation period at 13:00. The gray bars in the background indicate the measured maximum LAI at each level in the reference year. 


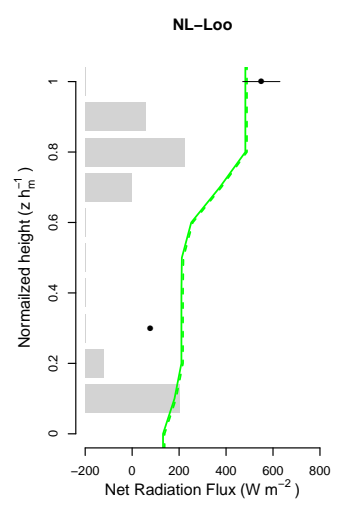

FI-Hyy

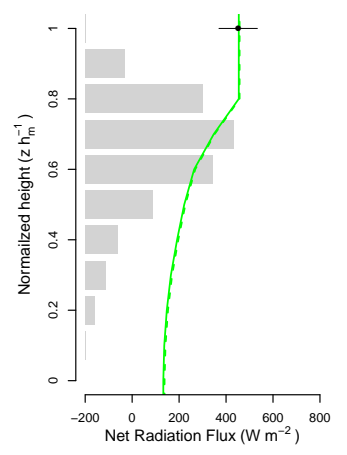

FR-LB

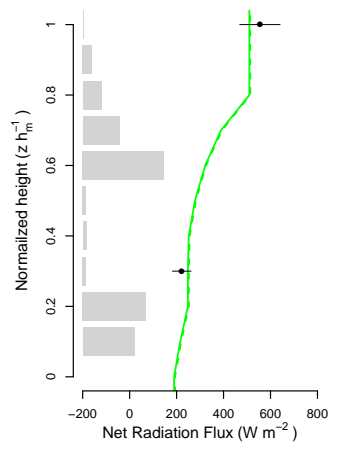

DE-Bay

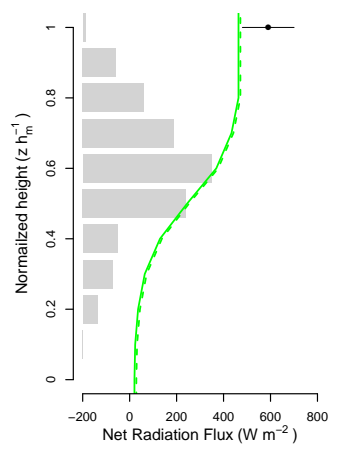

CA-Oas

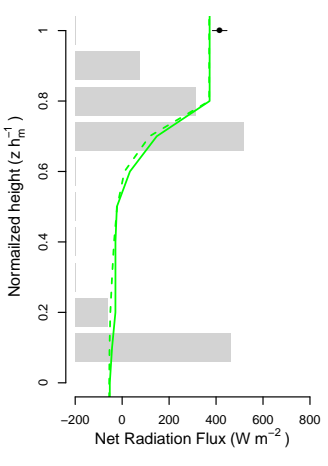

DE-Hai

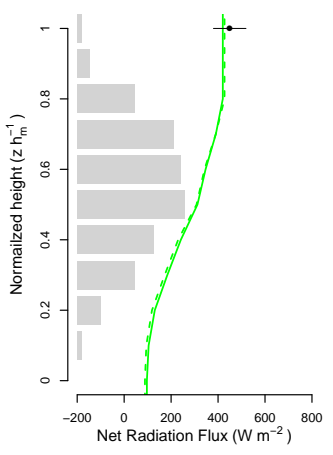

AU-Tum

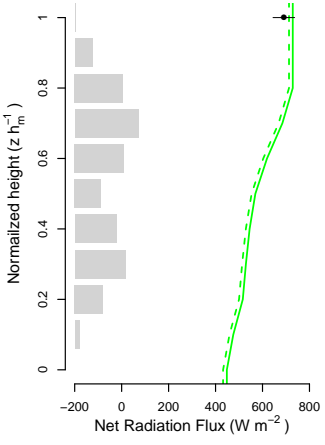

BE-Vie

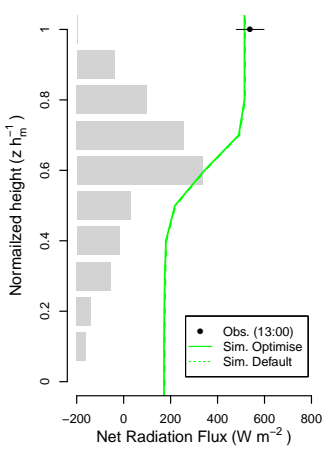

Figure S4. Model simulation and observation of the net radiation profile at eight forest sites during the shortterm campaign (Period I). All the dashed lines indicate the prior simulation with default parameter values and the solid lines present the optimized simulation with optimized parameter values. The filled circles are the observation means and the bars are stand deviations over the simulation period at 13:00. The gray bars in the background indicate the measured maximum LAI at each level in the reference year. 

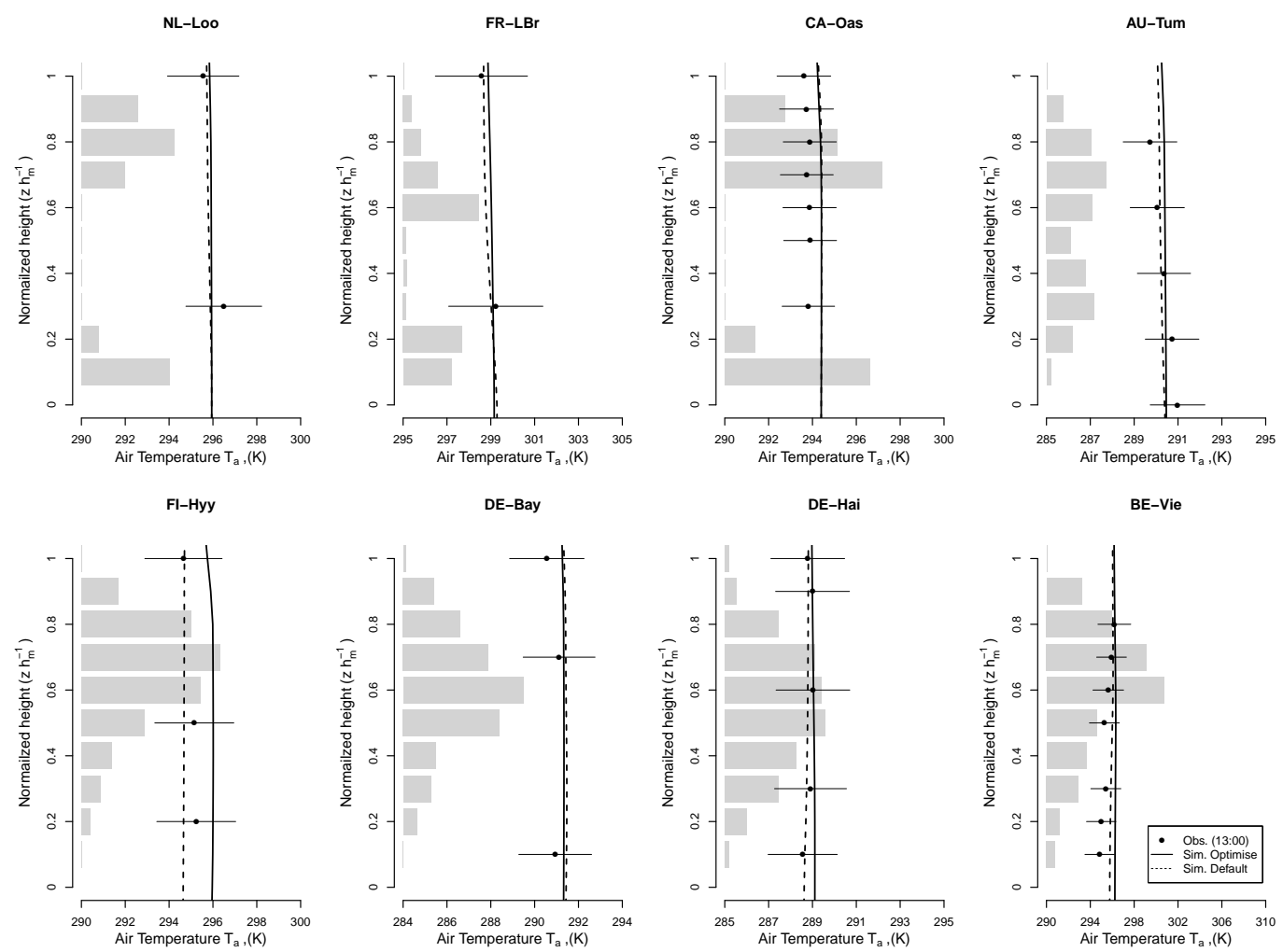

Figure S5. Model simulation and observation of the air temperature profile at eight forest sites during the short-term campaign (Period I). All the dashed lines indicate the prior simulation with default parameter values and the solid lines present the optimized simulation with optimized parameter values. The filled circles are the observation means and the bars are stand deviations over the simulation period at 13:00. The gray bars in the background indicate the measured maximum LAI at each level in the reference year. 

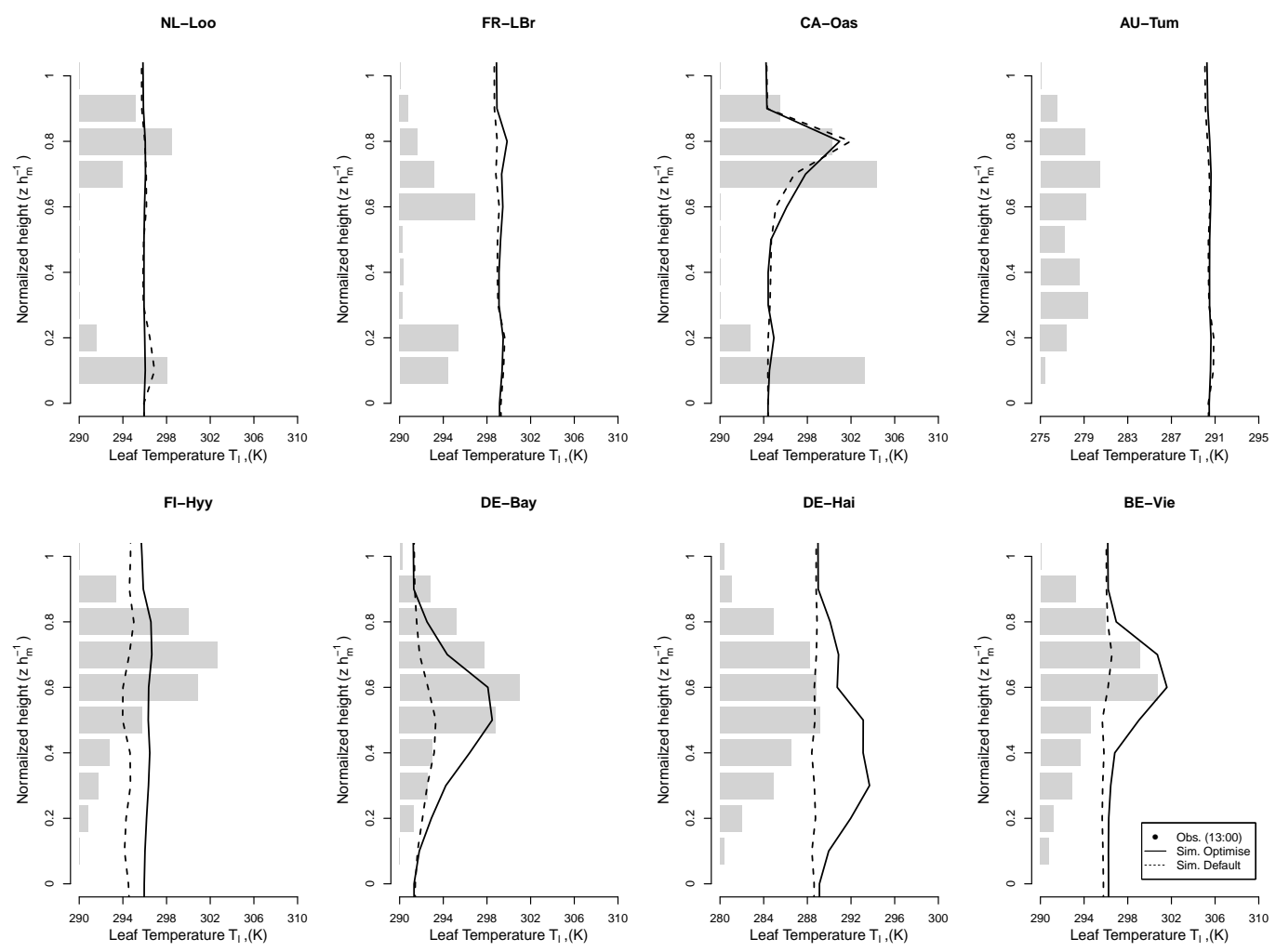

Figure S6. Model simulation and observation of the leaf temperature profile at eight forest sites during the short-term campaign (Period I). All the dashed lines indicate the prior simulation with default parameter values and the solid lines present the optimized simulation with optimized parameter values. The filled circles are the observation means and the bars are stand deviations over the simulation period at 13:00. The gray bars in the background indicate the measured maximum LAI at each level in the reference year. 

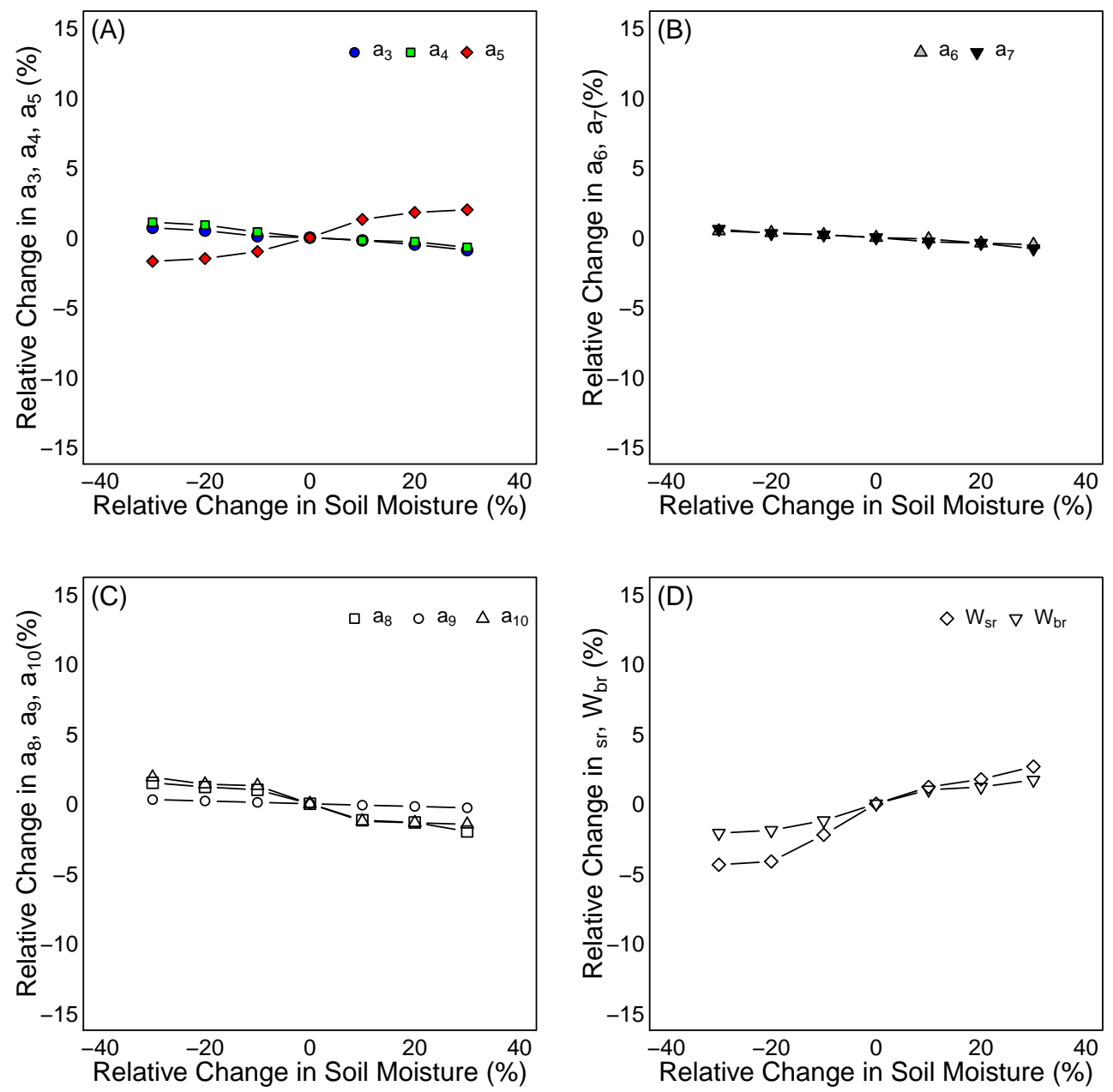

Figure S7. Sensitivity test of using default $k_{\text {surf }}$ value with different initial soil moisture conditions to determine optimized parameter values for short term period at FR-LBr site. (A) parameters from $a_{3}$ to $a_{5}$ to determine the effective surface drag coefficient, $C_{D e f f}(\mathrm{~B})$ parameters $a_{6}$ and $a_{7}$ to determine the weighting factor for eddy diffusivity, $W_{n f}(\mathrm{C})$ parameter from $a_{8}$ to $a_{10}$ to determine the weighting factor for surface-air interface conductance, $W_{s f}$ (D) weighting factor for stomatal resistance $W_{s r}$ and boundary layer resistance $W_{b r}$, respectively. 

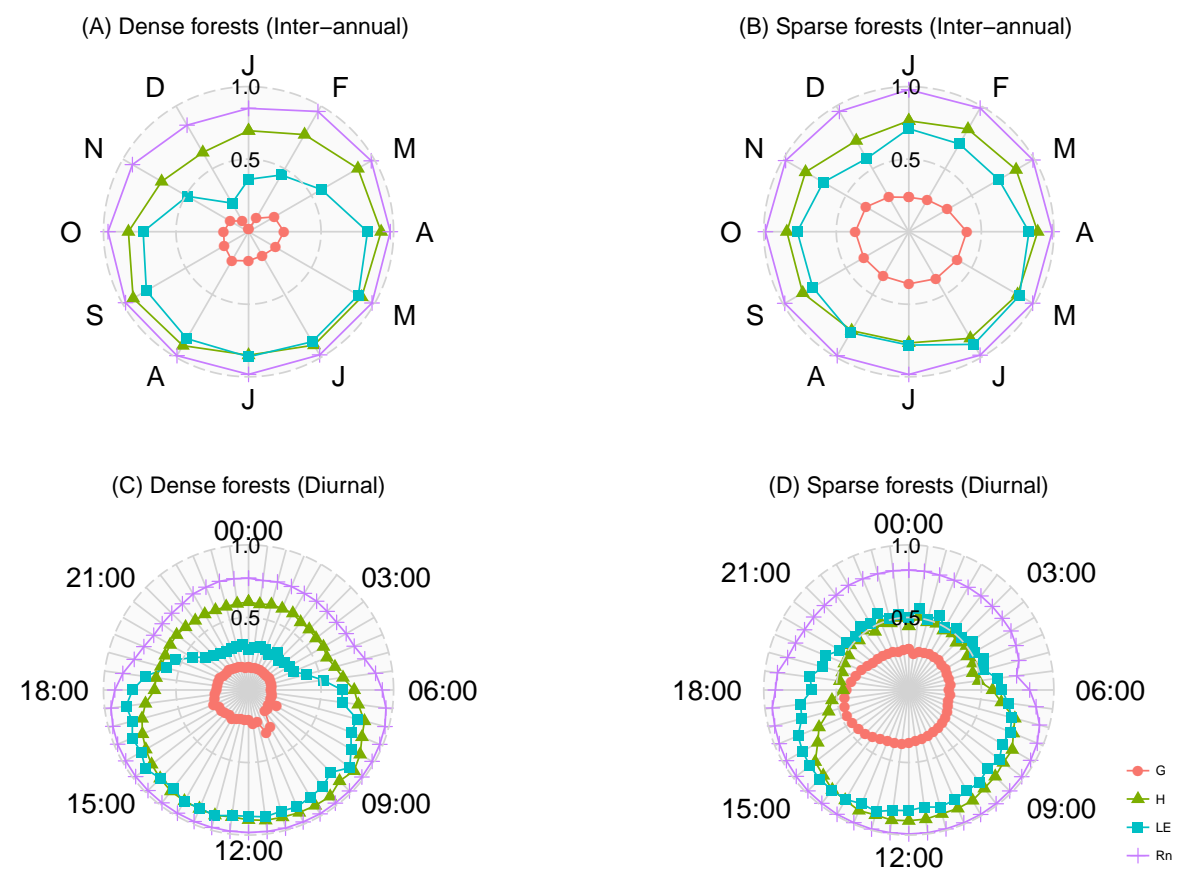

Figure S8. Model performance of the experiment 4 (EXP4) without the deciduous forest sites, CA-Oas and DE-Hai. 